\title{
One-Pot Synthesis of the Tetracyclic Framework of the Aromatic Erythrina Alkaloids from Simple Furans
}

\author{
Dimitris Kalaitzakis, Tamsyn Montagnon, Eirini Antonatou and \\ Georgios Vassilikogiannakis*
}

Department of Chemistry, University of Crete, Vasilika Vouton, 71003 Iraklion, Crete, Greece

vasil@chemistry.uoc.gr

Received Date (will be automatically inserted after manuscript is accepted)

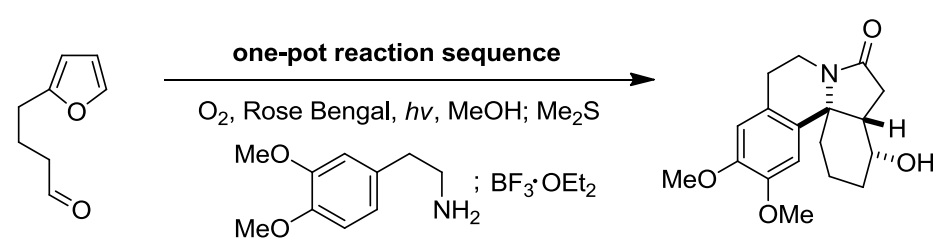

Conversion of a simple furan into the intact erythrinane skeleton in one synthetic operation has been accomplished. The one-pot reaction sequence begins with singlet oxygen photooxygenation of the furan and proceeds via a 2pyrrolidinone formation, cyclization of the pendant aldehyde moiety and an $\mathrm{N}$-acyliminium ion formation and terminates with a Pictet-Spengler-type aromatic substitution. The method has been used to achieve a rapid and highly effective formal synthesis of erysotramidine.

The aromatic (D ring) erythrina alkaloids (Figure 1) have long captured researchers' imaginations due to their characteristic and wide-ranging profile which combines a complex web of biogenetic relationships, potent biological activities, and synthetically challenging polycyclic molecular architectures. ${ }^{1}$ Strategies for the assembly of their tetracyclic frameworks are, as expected, numerous, ${ }^{2,3,4}$ but, right from the outset, ${ }^{5}$ construction

(1) (a) Dyke, S. F.; Quessy, S. N. In The Alkaloids; Rodrigo, R. G. A., Ed.; Academic Press: New York, 1981; Vol. 18, pp 1-98. (b) Sano, T.; Tsuda, Y. In The Alkaloids; Cordell, G. A., Ed; Academic Press: New York, 1996; Vol. 48, pp 249-337.

(2) For a review of the strategies used, see; Reimann, E. Synthesis Pathways to Erythrina Alkaloids and Erythrina Type Compounds. In Progress in the chemistry of organic natural products; Herz, W., Falk, H., Kirby, G. W., Eds.; Springer-Verlag/Wien: Austria, 2007; Vol. 88, pp 1-62.

(3) For selected example syntheses of aromatic erythrina alkaloids of the last decade using a Pictet-Spengler/NAI cyclization for C5-C13 bond formation, see; (a) Ogawa, S.; Iida, N.; Tokunaga, E.; Shiro, M.; Shibata, N. Chem. Eur. J. 2010, 16, 7090. (b) Juma, B.; Adeel, M.; Villinger, A.; Reinke, H.; Spannenberg, A.; Fischer, C.; Langer, P. Adv. Synth. Catal. 2009, 351, 1073. (c) Tietze, L. F.; Tölle, N.; Kratzert, D.; Stalke, D. Org. Lett. 2009, 11, 5230. (d) Zhang, F.; Simpkins, N. S.;
Blake, A. J. Org. Biomol. Chem. 2009, 7, 1963. (e) Tietze, L. F.; Tölle, N.; Noll, C. Synlett 2008, 525. (f) Zhang, F.; Simpkins, N. S.; Wilson, C. Tetrahedron Lett. 2007, 48, 5942. (g) Padwa, A.; Wang, Q. J. Org. Chem. 2006, 71, 7391. (h) Wang, Q.; Padwa, A. Org. Lett. 2006, 8 , 601. (i) Gao, S.; Tu, Y. Q.; Hu, X.; Wang, S.; Hua, R.; Jiang, Y.; Zhao, Y.; Fan, X.; Zhang, S. Org. Lett. 2006, 8, 2373. (j) Blake, A. J.; Gill, C.; Greenhalgh, D. A.; Simpkins, N. S.; Zhang, F. Synthesis 2005, 3287. (k) Allin, S. M.; Streetley, G. B.; Slater, M.; James, S. L.; Martin, W. P. Tetrahedron Lett. 2004, 45, 5493. (1) El Bialy, S. A. A.; Braun, H.; Tietze, L. F. Angew. Chem. Int. Ed. 2004, 43, 5391. (m) Padwa, A.; Lee, H. I.; Rashatasakhon, P.; Rose, M. J. Org. Chem. 2004, 69, 8209. (n) Lee, H. I.; Cassidy, M. P.; Rashatasakhon, P.; Padwa, A. Org. Lett. 2003, 5, 5067. (o) Gill, C.; Greenhalgh, D. A.; Simpkins, N. S. Tetrahedron Lett. 2003, 44, 7803. (p) Guerrero, M. A.; Cruz-Almanza, R.; Miranda, L. D. Tetrahedron 2003, 59, 4953. (q) Chikaoka, S.; Toyao, A.; Ogasawara, M.; Tamura, O.; Ishibashi, H. J. Org. Chem. 2003, 68, 312. (r) Abelman, M. M.; Curtis, J. K.; James, D. R. Tetrahedron Lett. 2003, 44, 6527.

(4) For selected example syntheses of aromatic erythrina alkaloids of the last decade not using a Pictet-Spengler/NAI cyclization for C5C13 bond formation, see; (a) Joo, J. M.; David, R. A.; Yuan, Y.; Lee, C. Org. Lett. 2010, 12, 5704. (b) Tuan, L. A.; Kim, G. Bull. Korean Chem. Soc. 2010, 31, 1800. (c) Liang, J.; Chen, J.; Liu, J.; Li, L.; Zhang, H. Chem. Commun. 2010, 46, 3666. (d) Onoda, T.; Takikawa, Y.; Fujimoto, T.; Yasui, Y.; Suzuki, K.; Matsumoto, T. Synlett 2009, 1041. (e) Yoshida, Y.; Mohri, K.; Isobe, K.; Itoh, T.; Yamamoto, K. J. Org. Chem. 2009, 74, 6010. (f) Stanislawski, P. C.; Willis, A. C.; Banwell, M. G. Chem. Asian J. 2007, 2, 1127. (g) Shimizu, K.; 


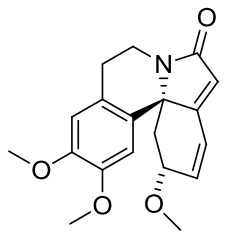

1: Erysotramidine

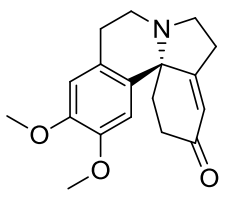

3: 3-Demethoxyerythratidinone

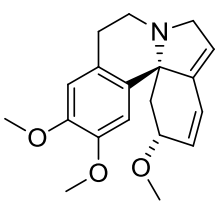

2: Erysotrine

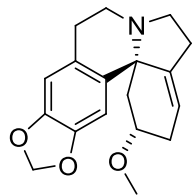

4: Erythramine

Figure 1. Selected erythrina alkaloids (with an aromatic D ring)

of the C5-C13 bond (completing the C-ring, Figure 1) by means of a Pictet-Spengler-type cyclization (in which an $N$-acyliminium ion ${ }^{6}$ acts as the electrophile in a substitution reaction with the aromatic moiety) has emerged as a particularly versatile approach. ${ }^{2,3,5}$ It should be noted that the aromatic erythrina alkaloids can be subdivided into two categories the dienoid type ( $\mathbf{1}$ and $\mathbf{2}$, Figure 1) which have a diene unit spanning the $A$ and $B$ rings and the alkenoid type ( 3 and $\mathbf{4}$, Figure 1 ) which have a single isolated double bond in the A ring. Despite the existence of a large body of synthetic work targeting both the dienoid and alkenoid erythrina alkaloids, only very rarely have researchers successfully constructed all the requisite non-aromatic rings ( $\mathrm{A}, \mathrm{B}$ and $\mathrm{C})$ in the same reaction sequence. ${ }^{7}$ Herein, we report the successful development of such a process that delivers the entire erythrinane skeleton in one synthetic operation, using exceptionally mild reaction conditions. The one-pot reaction sequence involves, but is by no means limited to, an $N$-acyliminium ion (NAI) formation and a PictetSpengler-type reaction and begins from simple and readily accessible furan precursors. It is important for the efficiency of the process that there is no lengthy substrate synthesis beforehand (Scheme 1). The development of this novel process was facilitated by our recent discovery of a new way to access NAIs beginning

Takimoto, M.; Sato, Y.; Mori, M. J. Organomet. Chem. 2006, 691, 5466. (h) Stanislawski, P. C.; Willis, A. C.; Banwell, M. G. Org. Lett. 2006, 8, 2143. (i) Kim, G.; Kim, J. H.; Lee, K. Y. J. Org. Chem. 2006, 71, 2185. (j) Yasui, Y.; Suzuki, K.; Matsumoto, T. Synlett 2004, 619. (k) Fukumoto, H.; Esumi, T.; Ishihara, J.; Hatakeyama, S. Tetrahedron Lett. 2003, 44, 8047. (1) Shimizu, K.; Takimoto, M.; Mori, M. Org. Lett. 2003, 5, 2323.

(5) For the earliest pioneering synthetic approaches, see; Belleau, B. J. Am. Chem. Soc. 1953, 75, 5765. (b) Mondon, A. Angew. Chem. 1956, 68, 578. (c) Prelog, V. Angew. Chem. 1957, 69, 33.

(6) (a) Speckamp, W. N.; Hiemstra, H. Tetrahedron 1985, 41, 4367. (b) Maryanoff, B. E.; Zhang, H.-C.; Cohen, J. H.; Turchi, I. J.; Maryanoff, C. A. Chem. Rev. 2004, 104, 1431.

(7) Padwa, A.; Hennig, R.; Kappe, C. O.; Reger, T. S. J. Org. Chem. 1998, 63, 1144 .

Scheme 1. Mechanistic rationale for the proposed one step synthesis of erythrinanes from simple furans

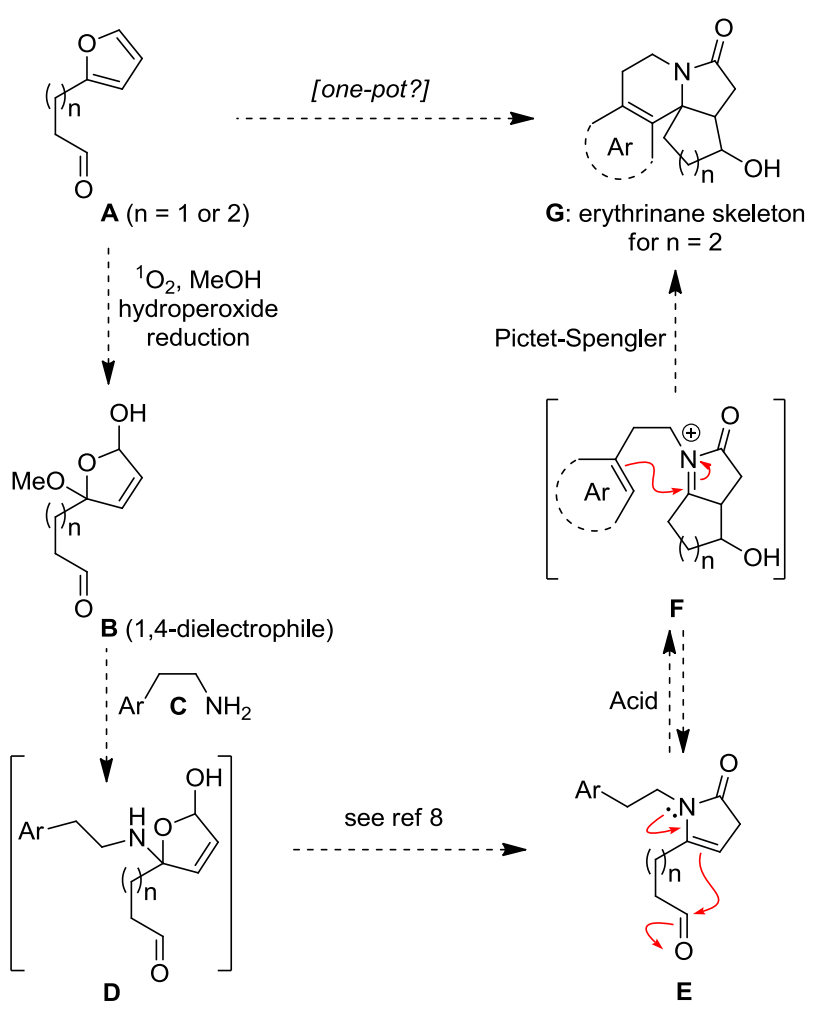

with singlet oxygen-mediated furan photooxygenation. ${ }^{8}$

This one-pot reaction sequence is notable particularly for its concise and rapid increase in molecular complexity from a very simple starting point (outlined mechanistically in Scheme 1). In this way it exhibits a very high degree of step $-{ }^{9}$ and atom-economy ${ }^{10}$ and this feature, in combination with its utilization of the selective green reagent, singlet oxygen, to mediate the changes with precision and minimal waste, mean that it succeeds in attaining many of the recently established criteria for an ideal synthesis. ${ }^{11}$ Furthermore, it intrinsically exhibits a number of other unique and highly advantageous characteristics. Firstly, the 1,4-dielectrophile (B, Scheme 1) accessed by singlet oxygen oxidation of a furan $(\mathbf{A} \rightarrow$ $\mathbf{B}$ in itself a mild and highly selective process with broad functional group tolerance) is of a specific nature such that the subsequent condensation with an amine $(\mathbf{B} \rightarrow \mathbf{E})$ can be achieved under milder conditions than when other

(8) (a) Kalaitzakis, D.; Montagnon, T.; Alexopoulou, I.; Vassilikogiannakis, G. Angew. Chem. Int. Ed. 2012, 51, 8868. (b) Kalaitzakis, D.; Montagnon, T.; Antonatou, E.; Bardají, N.; Vassilikogiannakis, G. Chem. Eur. J. DOI: 10.1002/chem.201301571.

(9) Wender, P. A.; Miller, B. L. Nature 2009, 460, 197.

(10) Trost, B. M. Science 1991, 254, 1471.

(11) (a) Young, I. S; Baran, P. S. Nature Chem. 2009, 1, 193. (b) Gaich, T.; Baran, P. S. J. Org. Chem. 2010, 75, 4657. (c) Newhouse, T.; Baran, P. S.; Hoffmann, R. W. Chem. Soc. Rev. 2009, 38, 3010. For the first introduction to the "ideal synthesis" concept, see: (d) Hendrickson, J. B. J. Am. Chem. Soc. 1975, 97, 5784. 
Scheme 2. One step synthesis of erythrinanes from simple furans

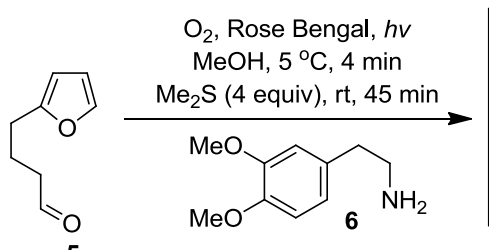

(0.8 equiv), rt, $30 \mathrm{~min}$

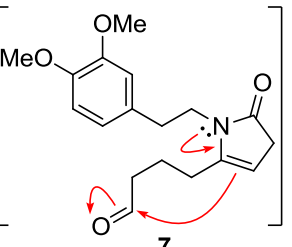

7

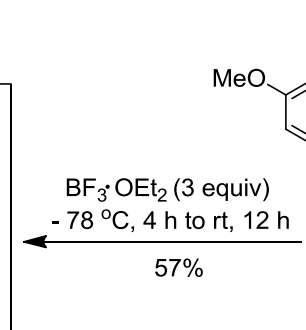

10

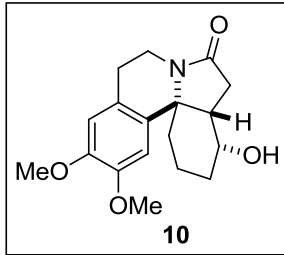

$\mathrm{BF}_{3} \cdot \mathrm{OEt}_{2}$ ( 3 equiv)

$57 \%$
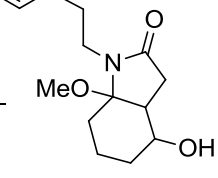

$54 \%$

8

TFA ( 0.5 equiv $)$

159\%
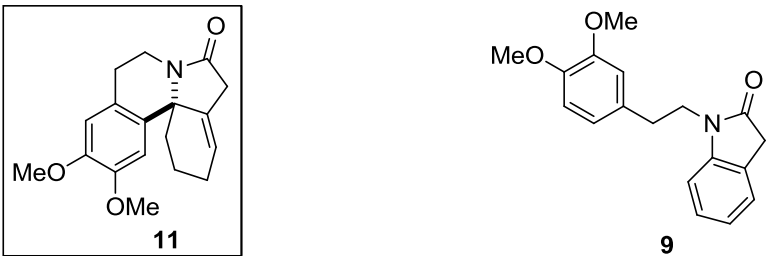

9

1,4-dielectrophiles of a more classical nature are used. ${ }^{6}$ This endows the overall process with broad enough functional group tolerance to allow a sensitive aldehyde moiety to be carried through to the end of the sequence whereby intermediate $\mathbf{E}$ is converted into $\mathbf{F}$ (Scheme 1). Secondly, the way this one-pot process has been designed allows us first to exploit the enamide's (E) nucleophilicity and then the NAI's (F) electrophilicity. Since interconversion of the enamide $\mathbf{E}$ and NAI $\mathbf{F}$ is relatively easy (via protonation/deprotonation), it should be noted that a reversal in the order of reactivity would terminate this particular sequence without construction of the A-ring of the erythrinane skeleton; so the relative reactivity (between the C-ring forming reaction and Aring forming reaction) needed to be right to ensure success. Our investigations, delineated below, have established the conditions needed to achieve the desired results and have shown how changes to those employed in the Pictet-Spengler step can be used to tailor the outcome to access both dienoid and alkenoid erythrina structures, as desired.

Furyl aldehyde $\mathbf{5}^{12}$ was used as substrate in the search for optimized reaction conditions (Scheme 2). In the first

(12) For full details of synthesis of these compounds and all one-pot procedures, see Supporting Information.

Scheme 3. Formic acid-mediated double electrophilic aromatic substitution

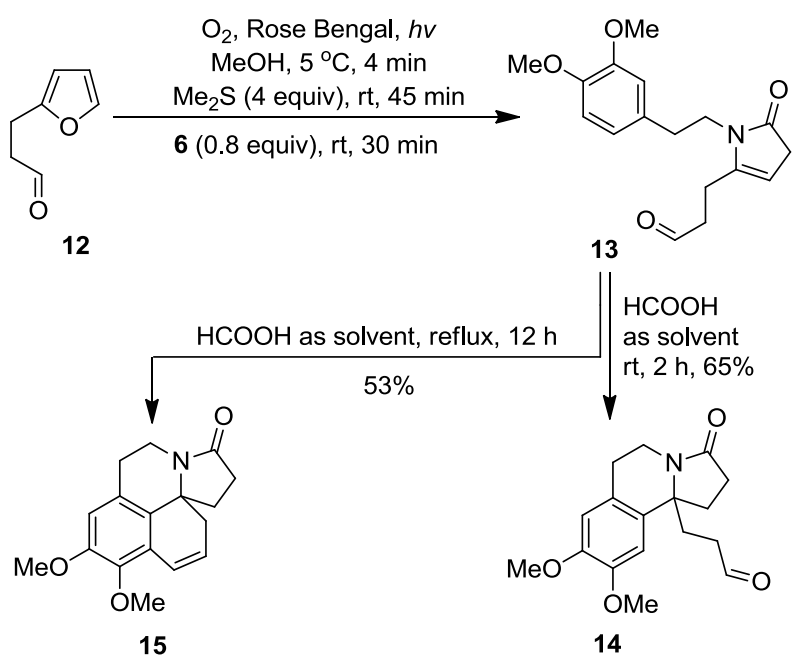

part of the one-pot process, $\mathbf{5}$ was subjected to a standard set of photooxygenation conditions ${ }^{8}$ and then condensed with amine 6 to furnish the enamide 7 which cyclized spontaneously to afford the fused bicycle and NAIprecursor 8. This was then treated in situ with one of a range of Brønsted and Lewis acids. Treatment with TFA (0.5 equiv, rt, $30 \mathrm{~min})$ yielded an aromatized product oxindole 9. Likewise, neat formic acid gave a complex mixture of desired product $\mathbf{1 0}$ (as its formate ester) and undesired by-products. However, when we turned our attention towards Lewis acids, the reaction immediately took on the desired profile. When $\mathrm{BF}_{3} \cdot \mathrm{OEt}_{2}$ ( 3 equiv) was introduced at $-78{ }^{\circ} \mathrm{C}$, at the appropriate moment in the one-pot procedure (i.e. when tlc analysis indicated the presence of cyclized compound $\mathbf{8}$ ), and the reactants were stirred for $16 \mathrm{~h}$, tetracyclic compound $\mathbf{1 0}$ was isolated ${ }^{12}$ in a remarkable $57 \%$ yield. The spectroscopic data of $\mathbf{1 0}$ are in full agreement with those already reported in the literature. $^{3 c, j}$ Thus, we had succeeded in finding the first conditions that would convert simple furan $\mathbf{5}$ into the intact erythrinane skeleton in a one-pot process. Furthermore, we had achieved a racemic formal synthesis of erysotramidine $\mathbf{1}$ (Figure 1) by a late stage intersection with Simpkins' asymmetric total synthesis. ${ }^{3 \mathrm{~d},} \mathrm{j}$ More specifically, erythrinane $\mathbf{1 0}$ is just four steps from erysotramidine $\mathbf{1}$ using the chemistry developed previously (Simpkins ${ }^{3 \mathrm{~d}, \mathrm{j}}$ and $\operatorname{Padwa}^{3 \mathrm{n}}$ ).

It was subsequently found that $\mathrm{AlCl}_{3}$ (4 equiv) was also a successful mediator of the desired reaction. In this case, however, we isolated tetracycle 11. The result of this modification was fortuitous, because tetracycle $\mathbf{1 1}$ has an A-ring double bond positioned correctly for the alkenoid aromatic erythrinane alkaloids such as 3demethoxyerythratidinone $\mathbf{3}$ and erythramine 4 (Figure 
1), to enhance the versatility of this newly developed chemistry.

We next sought to investigate how the outcome of this one-pot process might be affected if we made the A-ring formation less favorable relative to the Pictet-Spenglertype aromatic substitution (C-ring formation, Scheme 3). To this end, we subjected aldehyde $\mathbf{1 2}^{12}$ (with one less carbon in the side chain when compared to aldehyde 5) to several variations of the cascade reaction sequence conditions. In this case, formic acid turned out to be the acid of choice, as other acids $\left(\mathrm{BF}_{3} \cdot \mathrm{OEt}_{2}, \mathrm{AlCl}_{3}\right.$ and TFA) tested led to complex mixtures of products and starting materials. When formic acid was employed, however, we observed interesting results; after $2 \mathrm{~h}$ at room temperature, aldehyde 14 was isolated (yield 65\%) showing that the Pictet-Spengler-type cyclization now occurred in preference to formation of a [5,5]-fused bicycle via cyclization of the intermediate 2pyrrolidinone 13 onto the aldehyde functionality. Furthermore, if the temperature applied to this stage of the one-pot sequence was elevated to reflux, tetracycle $\mathbf{1 5}$ was isolated (overall yield 53\%). In this case, the aromatic moiety had undergone two successive acidcatalyzed electrophilic aromatic substitutions - the first with the NAI and the second with the aldehyde functionality, followed by dehydration. Thus, once again the aldehyde moiety has been conserved through a complex cascade reaction sequence until it was needed to participate in a final ring forming reaction completing the synthesis of an intricate tetracycle.

In conclusion, a new, mild and highly efficient erythrinane synthesis is presented. Starting with very simple and readily accessible furan substrates, the erythrinane tetracycle could be rapidly accessed in one synthetic operation. The mechanistically complex (but operationally simple) one-pot reaction sequence employed, began with singlet oxygen-mediated oxidation of the initial furan substrate and continued via condensation of the resultant 1,4-dielectrophile with an amine; cyclization of the resultant enamide, acidcatalyzed $\mathrm{N}$-acyliminium ion formation and PictetSpengler aromatic substitution completed the sequence. The method has been used to achieve a formal synthesis of erysotramidine, the shortness and high overall yield of which, are without precedent.

Acknowledgment. The research leading to these results has received funding from the European Research Council under the European Union's Seventh Framework Programme (FP7/2007-2013)/ERC grant agreement no. 277588

Supporting Information Available. Experimental procedures, full spectroscopic data and copies of ${ }^{1} \mathrm{H}$ and ${ }^{13} \mathrm{C}$-NMR spectra for all new compounds. This material is available free of charge via the Internet at http://pubs.acs.org. 